\title{
Paparan Iklim Kerja Panas Terhadap Status Hidrasi Pekerja Unit Produksi di PT. Argo Pantes Tbk Tangerang
}

\author{
Rulyenzi ${ }^{1 \mathrm{a})}$ \\ ${ }^{1}$ Program Studi Teknik Mesin ITI, \\ Jl. Raya Puspiptek Serpong, Tangerang Selatan-Banten, Indonesia, 15320 \\ a)rulyenzi_rasyid@yahoo.com
}

\begin{abstract}
ABSTRAK
Dehidrasi yang ditandai dengan kekurangan cairan pada tubuh merupakan gejala awal seseorang mengalami stres akibat tekanan panas. Dehidrasi dapat menyebabkan penurunan performa kerja hingga menimbulkan dampak kesehatan yang serius seperti gangguan fungsi ginjal dan jantung, bahkan kematian. Kondisi dehidrasi dapat disebabkan oleh faktor paparan tekanan panas dari lingkungan kerja serta faktor internal pekerja (usia, jenis kelamin, indeks massa tubuh, konsumsi cairan, beban kerja, dan shift kerja). PT. Argo Pantes Tbk merupakan perusahaan tekstil yang memiliki sistem operasi mesin 24 jam dalam proses produksi dengan pengaturan tekanan panas yang juga tinggi. Hasil studi pendahuluan menunjukkan 14 dari 23 pekerja mengalami dehidrasi dengan nilai indeks panas sebesar $103^{\circ} \mathrm{F}$ atau $39,4^{\circ} \mathrm{C}$. Penelitian ini bertujuan untuk mengetahui hubungan antara faktor paparan/pajanan panas dalam indeks Wet Bulb Globe Temperature Indoor (WBGTi) dan faktor internal individu terhadap status hidrasi pekerja. Desain penelitian yang digunakan adalah cross sectional dengan menggunakan uji statistik chi-square. Adapun status hidrasi diukur menggunakan berat jenis urine. Sample penelitian ini berjumlah 73 pekerja. Berdasarkan hasil penelitian, pekerja yang mengalami dehidrasi sebanyak 44 pekerja (60,3\%). Hasil analisis bivariat menunjukkan bahwa ada hubungan antara shift kerja dengan kejadian dehidrasi (p value 0,004). Untuk mengantisipasi terjadinya dehidrasi di kalangan pekerja, perusahaan sebaiknya melakukan pemasangan kipas angin, blower, maupun jenis pendingin ruangan lainnya di tempat istirahat pekerja, mengaktivasi sistem ventilasi yang telah ada, memberikan proteksi penutup dari material besi antara sumber panas pada mesin dan pekerja di unit dyeing finishing, mengatur pola shift kerja, memberi pelatihan atau sosialisasi kepada pekerja untuk mendeteksi tanda tubuh saat mengalami dehidrasi.
\end{abstract}

Kata Kunci: berat jenis urine, dehidrasi, indeks WBGTi, konsumsi cairan, paparan panas, status hidrasi

\begin{abstract}
Dehydration is condition where the body fluid was decreased and also can be detected as early symptom of suffering heat stress. Dehydration can decrease work permormance and cause many serious health problems such as kidney disorders, disfunction of heart even fatality. Dehydration can caused by factor of exposure of heat temperature in working area and the individual internal factors (age, sex, body mass index, fluid intake, workload and work shift). PT. Argo Pantes Tbk is textille company which has 24 hours of operating system of machines in it's production prosces with high temperature setting. According to the early research, it's found that 14 of 23 workers were experienced dehydration with heat index value numbered $103^{\circ} \mathrm{F}$ or $39,4^{\circ} \mathrm{C}$. The aim of this research is to find the association between factor of heat exposure in index of WBGTi and the individual internal factors to hydration status of workers. The design of this reserach was cross sectional design with chi-square statistic test. Hydration status was known by measuring urine specific gravity. Sample of this research were 73 workers.The result showed that there were 44 workers (60,3\%) who experienced dehydration. Bivariate analysis showed that there was significant association between work shift variable with dehydration among workers ( $p$ value 0,004). To prevent dehydration among workers, the company should have to perform good cooling system in rest room such as fan, blower, etc, activate ventilation system that already exist, make a barrier between machines or heat sources and workers especially in dyeing finishing unit, arrange the work shift and rest cycle of workers, and provide socialiszation or training to the workers in order to make them well understand how to detect early body symptoms of dehydration.
\end{abstract}

Keywords: dehydration, fluid intake, heat exposure, hydration status, urine specific gravity, WBGT index

\section{PENDAHULUAN}

Status hidrasi adalah keadaan yang menggambarkan kondisi keseimbangan cairan tubuh. Apabila status hidrasi tubuh berada dalam keadaan tidak normal atau ketika cairan tubuh berada dalam keadaan kurang maka hal ini yang disebut dengan dehidrasi [10]. Dehidrasi dapat terjadi karena beberapa kondisi seperti kehilangan cairan melalui saluran pencernaan atau 
gastrointestinal sehubungan dengan diare, muntah, berkeringat berlebihan akibat aktivitas berat, pengaruh lingkungan bertekanan panas dan lain sebagainya.

Dehidrasi memiliki dampak yang buruk bagi tubuh manusia. Dehidrasi sedang atau saat tubuh kehilangan $2 \%$ cairan dari berat tubuh akan mengganggu mood serta performa kognisi manusia. Kementerian Kesehatan (2014) juga menyatakan bahwa dehidrasi 1 $2 \%$ akan mengakibatkan tubuh lemas dan kurang tenaga karena produksi energi yang kurang cukup. Termasuk pada pekerja, kejadian dehidrasi juga memiliki pengaruh terhadap kemampuan kinerja, baik kemampuan secara fisik maupun kemampuan berpikir. Lebih parah lagi ketika seseorang tidak mengonsumsi cairan yang cukup dan mengalami penurunan jumlah cairan tubuh sampai $10 \%$ akan berdampak pada kematian.

Di Australia, dari hasil studi terhadap para penambang ditemukan bahwa $58 \%$ atau hampir separuh dari 88 pekerjanya dilaporkan berada pada status hidrasi tidak normal atau mengalami dehidrasi saat bekerja. Sejumlah pekerja tersebut mengalami dehidrasi dilihat dari hasil pengukuran berat jenis urine di atas $>1,020$. Sebuah penelitian juga pernah dilakukan di kalangan pekerja pemotong tebu di El- Salvador, Amerika menunjukkan hasil bahwa terjadi hubungan yang signifikan antara pajanan panas saat bekerja dengan penurunan glomerulus filtration rate (GFR) pada ginjal. Hal tersebut juga disertai dengan kejadian dehidrasi yang konsisten di kalangan pekerjanya. Dehidrasi atau kekurangan cairan tubuh juga dapat berdampak pada fungsi organ vital jantung. Hal ini sesuai dengan hasil penelitian Carter (2005) yang melakukan penelitian eksperimen untuk melihat pengaruh lanjut dari status hidrasi terhadap aktivitas jantung.

Di Indonesia, sebuah penelitian telah dilakukan oleh peneliti sebelumnya tahun 2004 di dua buah pabrik di Cibitung, Jawa Barat dengan melihat beberapa penanda status hidrasi dari parameter biokimia darah. Hasilnya pekerja yang terpajan panas lebih berisiko mengalami dehidrasi dibanding yang tidak terpapar panas atau yang hanya duduk mengerjakan tugas administrasi saja $(\mathrm{P}=0,005)$. Penelitian lain yang mendukung yaitu Andayani (2013) yang melakukan pengukuran berat jenis urine pada 73 pekerja laki-laki di industri perakitan alat berat dengan rata-rata pajanan panas $32,6^{\circ} \mathrm{C}$ untuk mengetahui status hidrasinya. Hasil penelitian tersebut menunjukkan hanya $28,8 \%$ subjek yang memiliki status hidrasi baik. Sisanya ditemukan subjek mengalami pre-dehidrasi (dehidrasi ringan 37,0\% dan dehidrasi sedang $15,0 \%$ ), sedangkan yang mengalami dehidrasi berat sebesar 19,2\% .

PT. Argo Pantes Tbk Tangerang merupakan salah satu produsen tekstil dengan tenaga kerja sejumlah 2200 orang, 700 orang tenaga kerja tetap dan 1500 orang merupakan tenaga kerja kontrak. Proses produksinya melibatkan penggunaan berbagai mesin otomatis yang beroperasi selama 24 jam menjadikan lingkungan kerja terasa panas, pengap serta bising yang memajan pekerja selama bekerja. Pekerja juga berpotensi mengalami dehidrasi. Salah satu proses produksi berisiko yaitu pada tahapan pewarnaan menggunakan mesin padsteam dengan pengaturan suhu sangat tinggi yaitu antara 200$210^{\circ} \mathrm{C}$ agar zat warna terikat kuat dengan serat kain. Dari hasil studi pendahuluan yang telah dilakukan, peneliti menemukan 11 dari 23 pekerja mengalami dehidrasi. Berdasarkan perhitungan indeks panas dari keadaan suhu dan kelembaban di area produksi PT. Argo Pantes Tbk diperoleh nilai sebesar $103^{\circ} \mathrm{F}$ atau $39,4^{\circ} \mathrm{C}$ yang berarti memiliki tingkat risiko kategori tinggi Dari segi peraturan, telah tertera dalam UU Ketenagakerjaan No.13 Tahun 2003 juga disebutkan bahwa kesejahteraan pekerja/buruh adalah suatu pemenuhan kebutuhan dan/atau keperluan yang bersifat jasmaniah dan rohaniah, baik di dalam maupun di luar hubungan kerja, yang secara langsung atau tidak langsung dapat mempertinggi produktivitas kerja dalam lingkungan kerja yang aman dan sehat. Maka untuk mewujudkannya, sudah seyogyanya perusahaan melakukan upaya-upaya atau program yang berasaskan keselamatan dan kesehatan bagi pekerjanya. Penelitian bertujuan untuk mengetahui hubungan antara paparan iklim kerja panas dengan status dehidrasi karyawan bagian produksi PT Argopantes Tbk.

\section{METODE PENELITIAN}

Metode penelitian yang digunakan adalah metode kuantitatif analitik dengan desain crosssectional. Uji statistik yang digunakan adalah chi-square dan uji t-independen. Sampel penelitian ini merupakan pekerja di unit produksi PT. Argo Pantes Tbk berjumlah 73 pekerja. Untuk mengukur faktor internal pekerja seperti usia, jenis kelamin atau shift kerja instrumen yang digunakan adalah kuesioner. Sedangkan untuk mengukur keadaan tekanan panas lingkungan berupa perhitungan Indeks WBGTi (Wet Bulb Globe Temperature Indoor) menggunakan alat QUESTemp ${ }^{\circ} 36$ 3M. Konsumsi cairan pekerja direkam menggunakan kuesioner food recall 1x24 jam adopsi dari kuesioner Riset Kesehatan Dasar tahun 2010. Instrumen lainnya yang digunakan dalam penelitian ini antara lain urine reagen strip untuk berat jenis urine, timbangan dan mikrotoise untuk indeks massa tubuh, stopwatch untuk merekam waktu beban kerja, kalkulator, software Ms.Excel serta software untuk menganalisis data.

\section{HASIL PENELITIAN}

Hasil penelitian terhadap 73 responden penelitian yang mengalami dehidrasi adalah sebanyak 44 pekerja atau sebesar $60,3 \%$, dan responden yang tidak mengalami dehidrasi adalah sebesar 29 pekerja atau sebesar 39,7\% (lihat tabel 1). Adapun derajat dehidrasi yang dimiliki responden berbeda-beda tergantung dari nilai berat jenis urine yang terukur. Dari 44 pekerja yang mengalami dehidrasi, sebanyak 15 pekerja (20.5\%) mengalami dehidrasi sedang dan 29 pekerja $(39,7 \%)$ mengalami dehidrasi berat.

Pada analisis bivariat (tabel 2) menunjukkan hasil bahwa ada hubungan antara variabel shift kerja dengan kejadian dehidrasi ( $p$ value 0,004). Sedangkan variabel usia, jenis kelamin, indeks massa tubuh (IMT), beban kerja, dan paparan panas dalam indeks WBGTi tidak berhubungan $(P$ value $>0,05)$. Variabel konsumsi 
cairan yang diuji menggunakan uji statistik t-independen juga menunjukkan bahwa tidak ada beda rata-rata konsumsi cairan antara yang dehidrasi dan tidak dehidrasi dengan $\mathrm{P}$ value 0,647. Semua hasil ditunjukkan pada tabel 2. Guna mengetahui hubungan antara konsumsi cairan oleh pekerja dan status hidrasinya dilakukan dengan menggunakan Uji-t independen seperti yang dapat dilihat pada tabel 3 .

Dari tabel 3 diinformasikan bahwa dari 73 responden penelitian di unit produksi rata-rata konsumsi cairan dalam satuan liter dari 44 pekerja yang mengalami dehidrasi adalah 2,1337 liter dengan standar deviasi sebesar 0,9456 liter. Pekerja yang tidak mengalami dehidrasi berjumlah 29 orang memiliki rata-rata konsumsi cairannya adalah 2,2537 liter dengan standar deviasi sebesar 1,2821 liter. Dari hasil statistik, nilai probabilitas yang diperoleh sebesar 0,647 yang artinya pada alpha 5\% tidak terdapat perbedaan rata-rata konsumsi cairan antara pekerja yang mengalami dehidrasi dibandingkan dengan pekerja yang tidak mengalami dehidrasi.

Tabel 1. Status Hidrasi Pekerja Bagian Produksi yang diuji

\begin{tabular}{cccc}
\hline Variabel & Kategori & Frekuensi & Persentase \\
\hline \multirow{2}{*}{ Status Hidrasi } & Dehidrasi & 44 & $60,3 \%$ \\
\cline { 2 - 4 } & Tidak Dehidrasi & 29 & $39,7 \%$ \\
\hline Total & & 73 & $100 \%$ \\
\hline
\end{tabular}

Tabel 2. Hubungan Antara Variabel-Variabel Penelitian dengan Status Hidrasi Pekerja Unit Produksi PT. Argo Pantes Tbk

\begin{tabular}{|c|c|c|c|c|c|c|c|c|c|}
\hline \multirow{3}{*}{ No. } & \multirow{3}{*}{ Variabel } & \multirow{3}{*}{ Kategori } & \multicolumn{4}{|c|}{ Status Hidrasi } & \multirow{2}{*}{\multicolumn{2}{|c|}{ Total }} & \multirow{3}{*}{ PValue } \\
\hline & & & \multicolumn{2}{|c|}{ Dehidrasi } & \multicolumn{2}{|c|}{ Tidak Dehidrasi } & & & \\
\hline & & & $\mathrm{n}$ & $\%$ & $\mathrm{n}$ & $\%$ & $\mathrm{n}$ & $\%$ & \\
\hline \multirow{2}{*}{1.} & \multirow{2}{*}{ Usia } & Berisiko & 22 & 62,8 & 13 & 37,1 & 35 & 100 & \multirow{2}{*}{0,847} \\
\hline & & Tidak Berisiko & 22 & 57,8 & 16 & 42,1 & 38 & 100 & \\
\hline \multirow{2}{*}{2.} & \multirow{2}{*}{ Jenis Kelamin } & Laki-laki & 20 & 52,6 & 18 & 47,4 & 38 & 100 & \multirow{2}{*}{0,250} \\
\hline & & Perempuan & 24 & 68,6 & 11 & 31,4 & 35 & 100 & \\
\hline \multirow{2}{*}{3.} & \multirow{2}{*}{$\begin{array}{c}\text { Indeks MassaTubuh } \\
\text { (IMT) }\end{array}$} & Gemuk & 18 & 75,0 & 6 & 25,0 & 24 & 100 & \multirow{2}{*}{0,122} \\
\hline & & Normal & 26 & 53,1 & 23 & 46,9 & 49 & 100 & \\
\hline \multirow{3}{*}{4.} & \multirow{3}{*}{ Shift Kerja } & Pagi & 15 & 68,2 & 7 & 31,8 & 22 & 100 & \multirow{3}{*}{0,004} \\
\hline & & Siang & 18 & 81,8 & 4 & 18,2 & 22 & 100 & \\
\hline & & Malam & 11 & 37,9 & 18 & 62,1 & 29 & 100 & \\
\hline \multirow{2}{*}{5} & \multirow{2}{*}{ Beban Kerja } & Berat & 11 & 44,0 & 14 & 56,0 & 25 & 100 & \multirow{2}{*}{0,072} \\
\hline & & Sedang & 33 & 68,8 & 15 & 31,2 & 48 & 100 & \\
\hline \multirow{2}{*}{6.} & \multirow{2}{*}{ Indeks WBGTi } & Tidak Aman & 29 & 58,0 & 21 & 42,0 & 50 & 100 & \multirow{3}{*}{0,743} \\
\hline & & Aman & 15 & 65,2 & 8 & 34,8 & 23 & 100 & \\
\hline \multicolumn{3}{|c|}{ Total } & 44 & 60,3 & 29 & 39,7 & 73 & 100 & \\
\hline
\end{tabular}

Tabel 3. Hasil Uji t-independen Variabel Konsumsi Cairan Terhadap Status Hidrasi Pekerja

\begin{tabular}{lllll}
\hline $\begin{array}{c}\text { Jumlah konsumsi cairan } \\
\text { dalam lt }\end{array}$ & Mean & SD & $\mathrm{n}$ & P value \\
\hline $\begin{array}{l}\text { Status Hidrasi } \\
\text { Dehidrasi }\end{array}$ & 2,1337 & 0,94567 & 44 & \\
& & & & \\
\cline { 1 - 2 } Dehidrasi & 2,2537 & 1,28216 & 29 & \\
\hline
\end{tabular}




\section{KESIMPULAN}

1) Sebanyak $60,3 \%$ atau 44 pekerja mengalami dehidrasi dengan kategori dehidrasi sedang sebanyak 15 pekerja $(20,5 \%)$ dan dehidrasi berat sebanyak 29 pekerja $(39,7 \%)$.

2) Ada hubungan yang signifikan antara shift kerja dengan status hidrasi pekerja PT. Argo Pantes Tbk tahun 2016.

3) Tidak terdapat hubungan yang signifikan antara variabel usia, jenis kelamin, konsumsi cairan, beban kerja, dan pajanan panas (Indeks WBGTi) dengan status hidrasi pada pekerja.

4) Tidak ada beda rata-rata jumlah konsumsi cairan antara pekerja yang mengalami dehidrasi dengan yang tidak mengalami dehidrasi pada pekerja.

\section{REFERENSI}

[1] ACGIH (American Conference of Govermental Industrial Hygienist). 2001. Heat Stress. USA

[2] ACGIH (American Conference of Govermental Industrial Hygienist). 2006. TLVs and BEIs. USA

[3] Armstrong (2005). Hydration Assessment Techniques. International Life SciencesInstitute. Doi: 10.1301/nr.2005. jun. S40-S54

[4] Ashby L. and Parker. (2003). Dehydration: Update on Research Literature. COHFE (Centre for Human Factors and Ergonomics Report. ISSN 1174-1234. Vol.4 No.7, 2003

[5] Brunzel, Nancy A. 2013. Fundamental of Urine and Body Fluid Analysis 3rd Edition. Online. Diakses pada 6 Juni2016

[6] Budd, Grahame M. (2008). Wet-Bulb Globe Temperature (WBGT) - It's History and It's Limitation. Journal of Science and Medicine in Sport (2008) 11, 20-32

[7] Health and Safety Excecutive. 2013. Heat Stress in the Workplace: a Brief Guide. www.hse.gov.uk/pubns/indg451.htm

[8] Health and Safety Authority (HSA). 2012. Summary of Workplace Injury, Ilness and Fatality Statistics 2011-2012. ISBN No: 978-1-84496-182-5

[9] Dubin Hunt, Andrew Philip. (2011). Heat Strain, Hydration Statusand Symtomps of Heat Ilnessin Surface Mine Workers. Queensland University of Technology. Dissertation (Doctor of Phylosophy)

[10] Kementerian Kesehatan Republik Indonesia. (2015). Pedoman Kebutuhan Cairan Bagi Pekerja Agar Tetap Sehat dan Produktif. Jakarta : Kementerian Kesehatan RI 